\title{
News from Euromat 2015 and the 2015 Conference of Metallurgists
}

\section{new and noteworthy at TMS}

Turn to this regular JOM feature for information on new TMS initiatives, updates, and overviews of TMS events and activities, and news from the field that impacts TMS and its members. To submit news items for consideration, contact Lynne Robinson, JOM Contributing Editor, at Irobinson@tms.org.

\section{TMS Strengthens Global Ties at Euromat 2015}

TMS leadership laid the groundwork for future collaboration with the Federation of European Materials Societies (FEMS), while participating in the 2015 European Congress and Exhibition on Advanced Materials and Processes (Euromat 2015) in Warsaw, Poland, September 20-24. Euromat is organized every other year by FEMS, which is a non-profit association of 28 European materials societies.

Patrice Turchi, 2015 TMS President, and James J. Robinson, TMS Executive Director, kicked off the week of learning and relationship building on September 19 by attending Materials for Europe, an invitation-only forum organized

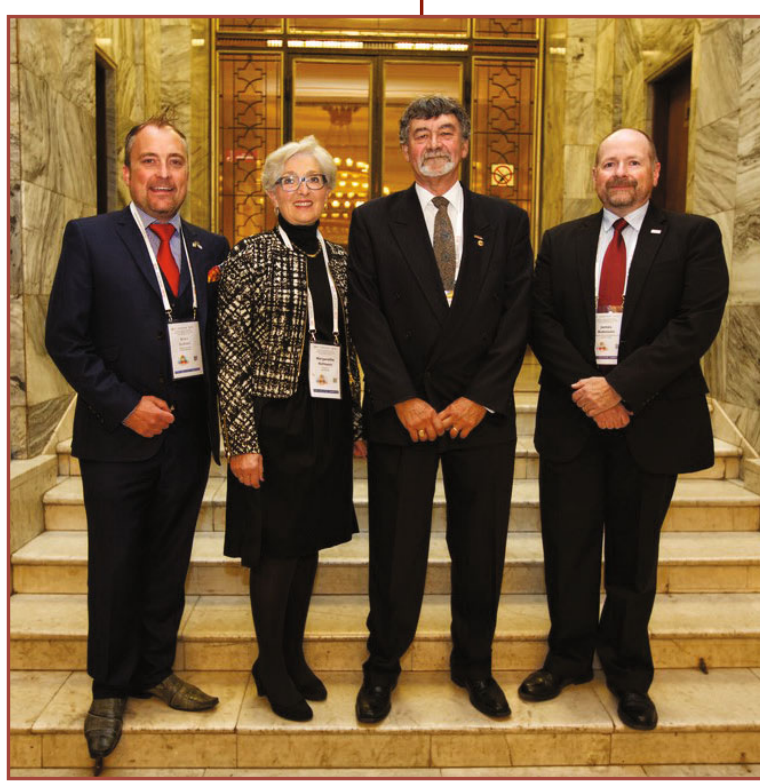

TMS and FEMS leadership met during the course of Euromat 2015 to discuss future potential collaborations. Pausing before the Euromat 2015 gala dinner are (left to right): Brett Suddell, FEMS Vice President, Margarethe Hofmann, FEMS President, Patrice Turchi, 2015 TMS President, and James J. Robinson, TMS Executive Director. by FEMS, the European Materials Research Society, and the European Materials Forum. Through a series of strategic presentations and roundtable discussion, meeting participants assessed progress and future challenges to establishing an open innovation framework and culture across Europe in materials research and development. Clara De La Torre, Director,
DG Research and Innovation, Directorate Key Enabling Technologies, European Commission (EU), opened the event with a policy overview of Horizon 2020, a legislatively mandated program that coordinates EU research and innovation funding within a common strategic framework. Marco Falzetti, chair, Managing Board of Alliance for Materials (A4M), followed with an update on the A4M initiative to facilitate integration of the materials value chain in Europe as a means of bringing innovations to market at an accelerated pace.

Turchi presented TMS's own efforts in advancing materials and manufacturing innovation, with a particular emphasis on global outreach priorities, at a meeting of the FEMS General Assembly on the following day. He highlighted the FEMS/TMS Young Leader International Scholar program as a highly successful collaboration to secure the future of the profession around the world. He also traced the history of the ABM-TMS Pan American Materials Congress as an example of how international materials societies can effectively partner to support the exchange of ideas on topics of common interest across cultures.

Turchi continued the conversation on TMS's strategic initiatives as Euromat 2015's opening plenary speaker. This was placed within the context of his technical talk, "What are First-Principles Methodologies Good For?", focusing on the current state and future potential of $a b$ initio approaches. At the conclusion of his presentation, he outlined TMS activities supporting the advancement of integrated computational materials science 
and engineering and the U.S. Materials Genome Initiative.

In addition to participating in technical sessions and networking events with the more than 1,200 other Euromat 2015 attendees, Turchi and Robinson met formally and informally with FEMS leadership to discuss the potential for joint projects. "This was an extremely positive experience that has strengthened TMS's relationship with FEMS," commented Turchi. "TMS and FEMS are actively exploring how we can potentially co-sponsor programming to advance scientific knowledge and technical capabilities, while also ensuring meaningful participation by TMS professional members and students throughout the world."

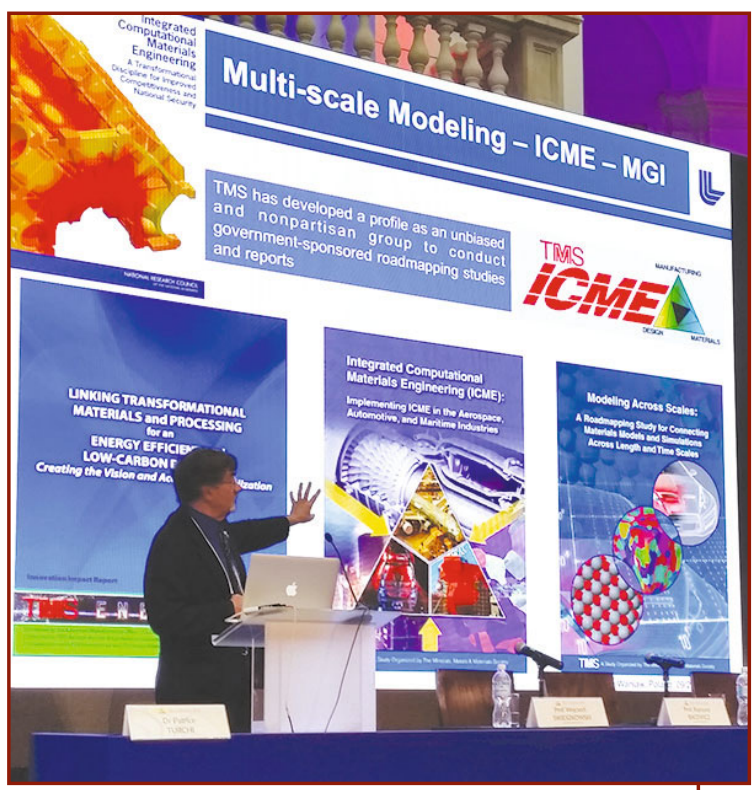

Patrice Turchi, TMS 2015 President, highlights a few of TMS's initiatives focused on advancing materials and manufacturing innovations during his opening plenary talk at Euromat 2015.

\section{MetSoc Celebrates Women of Impact}

The Metallurgy and Materials Society (MetSoc) of the Canadian Institute of Mining, Metallurgy, and Petroleum (CIM) highlighted the accomplishments of Canadian women in materials, mining, and metallurgy at its Women of Impact symposium on August 26, held in Toronto as part of the 2015 Conference of Metallurgists, co-sponsored by TMS.

An outgrowth of the work in developing the symposium was publication of Women of Impact, a book compiling biographical profiles, as well as interview excerpts, of 18 accomplished Canadian women in the minerals, metals, and materials professions. The book was authored by a TMS member, Mary Wells, who is the current MetSoc president and associate dean of outreach for the University of Waterloo Faculty of Engineering. Her coauthor is Anne Millar, a Ph.D. candidate in the Department of History, University of Ottawa. The full interview transcripts are available in the Canadian Women's Movement Archives, University of Ottawa. The book can be purchased at www.cim.org.

The symposium featured panel discussions with many of the women highlighted in the book, including Carolyn M. Hansson, professor, University of Waterloo, and 1997 TMS Fellow. Hansson was the first female student admitted to the Royal School of Mines at Imperial
College, London, and the first woman to graduate with a Ph.D. in metallurgy from the same institution. She provided some insight into the pressure of this groundbreaking role by relating words of caution given to her as a student by her department head: "Do you realize that if you fail at your degree, there will not be another girl admitted to a metallurgical program in this country

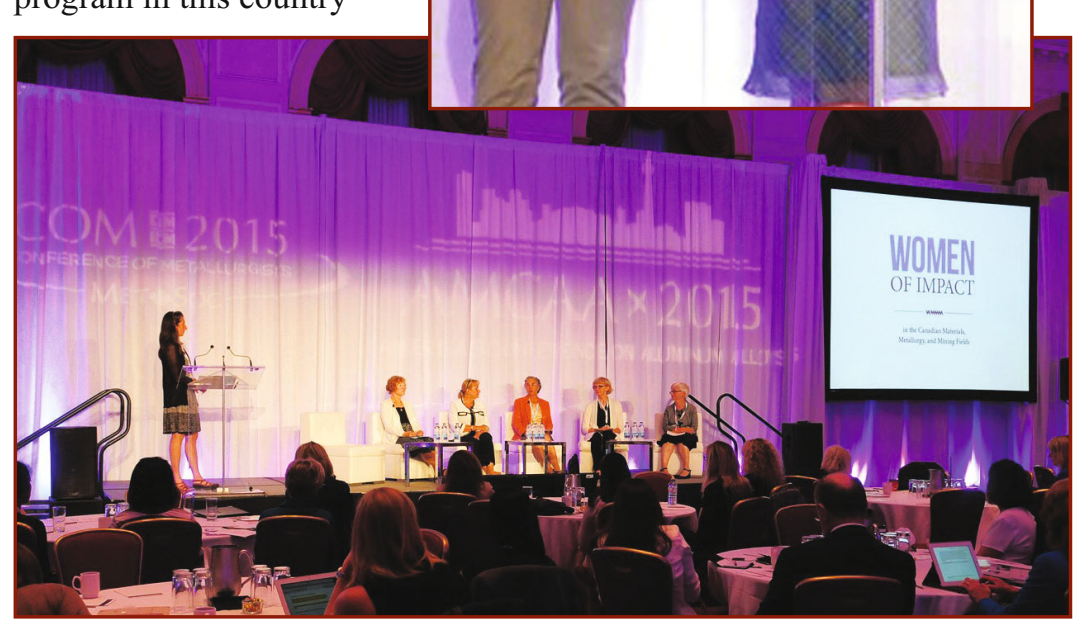

(Top photo): Anne Millar (left) and Mary Wells open the Women of Impact symposium, held as part of the MetSoc 2015 Conference of Metallurgists. (Bottom photo): The symposium featured presentations and panel discussions by individuals who have pioneered the role of women in the Canadian materials, mining, and metallurgical industries. 
for many years.'

A goal of MetSoc's Women of Impact initiative was to document, recognize, and share the accomplishments of women in science and engineering as a means of providing inspiration and role models for the next generation. Said Wells in her introductory remarks at the symposium, which she also organized, "We are seeing record high numbers of women entering the field. Not only do we need to keep them studying in school, but we also need to find ways to keep them engaged in the profession throughout their careers."

A TMS leadership group consisting of 2015 President Patrice Turchi, TMS Past President Hani Henein, TMS Vice President Stanley Howard, and James J. Robinson, TMS Executive Director, attended the symposium to gain insights for TMS's own diversity and inclusion initiatives. They also met with MetSoc leaders during the course of the conference on future collaborative efforts.

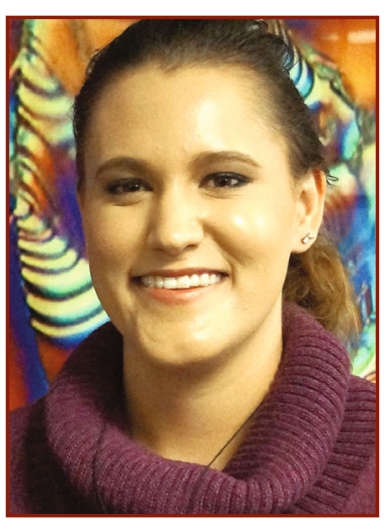

Laura Beringer

\section{Announcing the 2016 TMS Annual Business Meeting}

The Minerals, Metals \& Materials Society, Inc. (TMS) in accordance with its bylaws (Article II, Section 2.6) will hold its 2016 Annual Business Meeting on Wednesday, February 17, 2016 at 8:25 a.m. at the Omni Nashville Hotel, Nashville, Tennessee, USA, during the TMS 2016 Annual Meeting \& Exhibition. All TMS members are encouraged to attend this meeting.

\section{Laura Beringer Joins TMS Technical Team}

TMS welcomes Laura Beringer to its staff as the new technical specialist. She will work in the Technical Department with George Spanos, Technical Director, and Justin Scott, Technical Project Leader, to support the society's growth in the technology areas of focus in the TMS strategic plan.

Beringer earned her B.S. in biomedical engineering and her M.S. and Ph.D. in materials science and engineering, all at Drexel University. During her graduate studies, she worked in Drexel's Natural Polymer and Photonics Laboratory researching natural and synthetic polymer uses for projects involving biosensors and skin/bone tissue engineering. After graduation, Beringer moved to the Allegheny Singer Research Institute where she led the fabrication and implantation of novel adipocyte scaffold technology for breast cancer reconstruction and severe burn injuries in animal models.

"The technical strengths and knowledge that Laura brings to TMS are well aligned with advancing the strategic goals set by our board of directors," said Spanos. "In addition to her strong overall foundation in materials science and engineering, Laura's more specific background and research experience in biomedical materials science and engineering — in both industry and laboratory settings - will also help to grow TMS initiatives and bring new opportunities to our community. She will be a great asset in her work with the TMS volunteers and technical committees in driving the organization's progress."

"TMS strives to bring the minerals, metals, and materials science and engineering community together to strengthen the profession and focus on global challenges," added James J. Robinson, TMS Executive Director. "Our technical team makes a strong contribution to the vision and growth of the society. I am confident that Laura's knowledge and abilities will encourage our progress on these efforts. TMS is fortunate to have Laura as a part of the team."

"I feel privileged to be part of TMS and play a role in the big-picture issues that challenge our minerals, metals, and materials communities," Beringer said. "I look forward to contributing my expertise and talents to TMS-led technical initiatives that help our members and volunteers solve 21 st century challenges."

\section{JONM Seeks Reader Input}

JOM is conducting a readership survey of TMS members from January 4-18, 2016. The JOM editorial team will use the results to guide decisions on content and approaches to enhance JOMs value as the TMS membership journal. The survey will require roughly 15 minutes to complete.

TMS members will receive an e-mail with a link to the survey. Those who prefer a paper copy can contact Beate Helsel, TMS Marketing Data Analyst at bhelsel@tms.org. Make sure to take this opportunity to help shape JOMs future directions and complete the survey by January 18. 